\title{
Perspectives
}

\section{Short-Term Overseas Study Programs: A Survey of Private Junior High Schools in Tokyo}

\author{
Herbert E. Brauer \\ Hosei University, Second Junior High School
}

This survey research is the first large-scale study to provide a description of short-term overseas study programs implemented by private junior high schools in Tokyo. In addition to fundamental quantitative parameters, this comprehensive survey returned descriptive data from $84 \%$ of the private junior high schools in the Tokyo region with programs in 2001 and 2002. This descriptive data included types and details of activities undertaken, program and activity objectives, integration between the overseas study programs and school curricula, follow-up activities, and program evaluation. The survey revealed several innovative programs and activities implemented by these schools and identified areas that might benefit from further research.

本論文は、東京都の各私立中学校が行っている短期海外滞在プログラムの詳細を報告し たものである。各校から集めた数値的なデー夕にあわせて、84\%の学校からは、2001年度 から2002年度にかけて行われたプログラムの内容、目的、正規の授業との関連、事後指 導、評価方法などに関する定性的デー夕も収集した。本調査から各校でさまざまな試みが なされているものの、さらに調査を必要とする部分もあることがわかった。

I n 1996, the Japanese Ministry of Education conducted a survey of international exchange and study abroad programs and activities implemented by public and private senior (although not junior) high schools in Japan. That survey examined only the broadest parameters of the programs, such as the numbers of schools and pupils partici-

JALT Journal, Vol. 27, No. 1, May, 2005 
pating in longer-term ( 3 months or longer) or shorter-term (less than 3 months) sojourns, the countries visited, and the disposition of Japanese pupils returning from the longer-term programs (whether they repeated a year, continued to the next year, or graduated) (Mombukagakusho, 1998). However, neither independent researchers nor the Ministry appear to have undertaken any large-scale descriptive studies focusing on such aspects of these programs as objectives, extracurricular activities, English as a second language (ESL) classes (content and hours), and accommodation (e.g., single or double homestay, dormitory stay).

Some researchers in Japan have conducted studies on the effects of particular short-term study abroad programs. Most of these studies have examined college programs and concerned themselves with linguistic proficiency, attitudes to the target language or language community, personal changes, and cultural understanding. For example, Higuchi, Saito, Lamarche, Shelangouski, and Kikuchi (1982), Kitao (1993), and Nozaki (1987) examined the effects of short-term (approximately one month) study abroad programs on Japanese junior college students. Higuchi et al. focused on changes in interpersonal values and images of native speakers in the target culture, Nozaki considered changes in attitudes towards the target culture, and Kitao examined attitudes towards, and images of, host nationals as well as linguistic proficiency. All three studies provided evidence suggesting that even short-term sojourns had measurable effects upon student attitudes. A study by Geis and Fukushima (1997) also examined a six-week intensive language study program arranged between a Japanese junior college and a major university in the United States. Because the students stayed in dormitories with their compatriots, the group as a whole remained relatively isolated and cohesive; it was not until the end of the sojourn that the Japanese students finally began to make friends with English-speaking students. The researchers concluded that any observed effects were more likely the result of intensive English lessons than the result of contact with the target culture and language community. On the other hand, among the few studies that have considered secondary school pupils, some have either looked at long-term (one-year) programs (e.g., Yashima \& Viswat, 1991) or focused on individual student exchange within the framework of an international exchange program (e.g., Stitsworth \& Sugiyama, 1990).

There does not, however, seem to have been any research at all into short-term "summer language programs" implemented for junior high school pupils 12 to 15 years of age. Although not as numerous as those offered at senior high school or college levels, programs for pupils in 
the final year of junior high school may provide a particularly good opportunity for improving proficiency or attitudes towards English, which could, in turn, have a timely and positive impact upon language study in senior high school.

Some researchers have argued against the notion that there is either significant linguistic or cultural benefit from short-term overseas study programs (OSPs) (Day, 1987; Grove, 1983; Milleret, 1990). In particular, Grove claimed that programs lasting less than one month (a time frame that includes almost every short-term program implemented by the junior high schools in the current study, as well as the majority of programs at the senior high school level) not only fail to achieve their intended results, but may even be counterproductive and lead to undesired results. "Research and informed opinion suggest strongly that, in the case of a VSP (very short exchange program) (a) some important positive outcomes are not attainable, and that, (b) some undesirable outcomes are a likely result" (1983, p. 1). Moreover, in a previous paper, Grove discussed American Field Service programs, which include short-term sojourns for high school pupils (Grove, 1982). Therefore, it is reasonable to infer that his criticism would extend to VSPs organized for junior high school pupils. While Grove's remarks refer primarily to changes in longlasting attitudes towards people in the target culture and intercultural perspectives, both Day (1987) and Milleret (1990) refer specifically to circumstances that limit or restrict linguistic effects. In particular, Milleret, in her discussion of the difficulties involved in evaluating the outcomes of summer study programs, observes that "the living situation and location of the homestay may affect the opportunities each student has to experience linguistic and cultural growth" (1990, p. 486). Day reiterates Abrams' (1960) observation about the short length of summer study programs, which "may entail superficial contact with the host culture [and] inadequate language practice" (1987, p. 261).

Educators in Japan offer a somewhat different perspective. Although their observations are subjective, most of the teachers who responded to the current survey were very positive about the linguistic and cultural effects of these programs. Echoing a similar belief, Shiozawa writes: "There's no end to the benefits of overseas study or short-term study abroad trips. [Students] cultivate an objective perspective on Japan...develop confidence from relying on themselves...take notice of their insufficient communicative skills and return to Japan motivated to study English" (2001, p. 16) (translation by author). 


\section{Purpose}

The purpose of this study is to describe short-term OSPs administered by private junior high schools in Tokyo. To the best of my knowledge, there are no formally published materials about how these programs actually operate, what they attempt to achieve, or how many participants visit which countries and for how long. Nor are there descriptions of the activities these programs offer and how these activities are organized to provide opportunities for naturalistic as well as instructed exposure to the target language.

The present study describes a survey conducted in May and June of 2002 of OSPs that were implemented the previous spring (March 2002) or summer (July, August 2001) by private junior high schools in Tokyo. While these schools may not be representative of private junior high schools throughout Japan, this is an extremely populous region (approximately 12 million people) with a correspondingly large student population (over 312,000 junior high school pupils). Moreover, since short-term OSPs conducted by junior high schools are almost exclusively the domain of the private institutions, and over 32\% (75,711 in Tokyo, 233,553 nationwide) of private junior high school pupils in Japan attend schools in Tokyo (Mombukagakusho, 2001), the significance of those schools surveyed increases.

\section{Instrument and Procedures}

The questionnaire (Appendix I) contained 34 items arranged into six parts:

I. Respondents and schools

II. Time, duration, and destination of the OSP

III. Participating pupils

IV. Objectives, activities, and preparations for the OSP

V. Respondent's opinions about the OSP and participating pupils, and

VI. Follow-up and evaluation of the OSP.

To conserve space, Part V questions, which concerned respondents' opinions rather than specific program features and characteristics, have been omitted from this paper. 
The questions were created to take into consideration the major objectives and program features described in a variety of sources that have addressed the subject of study abroad for language learning. For example, Drysdale and Killelea (1982) provided a model for the organization of short-term language immersion programs for high school pupils and stressed the importance of proper orientation (predeparture) as well as follow-up activities. Milleret (1990) also mentioned orientation and reentry debriefing as well as the importance of homestays, and language and culture classes provided at the local institution as major program features. Brecht and Walton (1994) claimed that "the primary local conditions under which learning takes places in an SA [study abroad] program [are] preprogram preparation, in-country learning, and reintegration into the home institution" (p. 220). Within the context of "in-country learning," they referred not only to formal instruction, but also, especially, to the opportunities that can arise from informal, unstructured interaction. They were also critical of inadequate integration and follow-up, noting that "(a)n aspect of SA that has been virtually ignored is how the SA experience can be enhanced upon reentry into the domestic program" (p. 223). Coleman (1997) examined study abroad programs among tertiary institutions and found shortcomings in key aspects such as preparation, curriculum integration, support while abroad, and overall program evaluation (p. 3). In an article describing the benefits of, and criteria for, a successful study abroad program, Shiozawa (2001) referred to the importance of clear program objectives, predeparture orientation, and the need to make the most out of accommodation arrangements. These observations and concerns of other practitioners and researchers in the field informed the creation of the questions that comprised the present survey.

The questionnaire was originally drafted in English. A nonspecialist Japanese native speaker translated the questions into Japanese and a senior administrator of a Japanese junior high school checked them for appropriateness of style and expression. The questionnaire was then piloted by three colleagues (Japanese teachers of English with experience in chaperoning pupils on overseas study programs) who provided feedback on wording as well as on the overall amount of time it took to complete the questionnaire. Items were reworded accordingly; however, the length of the questionnaire was not reduced, even though it was recognized that a complete response might require about 30 minutes.

Private junior high schools in Tokyo currently implementing OSPs were identified by referring to the Chugakko Juken Annai $2002 \mathrm{Ny}$ - 
ushyo [2002 Guide to Entrance Examinations for Junior High Schools] published by Obunsha in April 2001. The volume provided school particulars and program descriptions for each of the 176 private junior high schools in Tokyo and identified 73 private junior high schools with OSPs.

Due to the relatively small number of schools with study abroad programs, it was decided not to sample this population but to request each of the 73 schools with programs to participate in the survey. Initially, either the principal, vice-principal or head teacher (kyotosensei) from each school was contacted by telephone to seek permission to mail the questionnaire. At that stage, only seven schools declined to participate, citing lack of time (four schools) or grounds of principle (three schools), and of the remaining 66 schools, five failed to return the questionnaire for various reasons. Thus, ultimately, 61 schools returned completed questionnaires. This yielded an extremely high response rate of 92 percent of questionnaires sent out and an overall participation rate of 84 percent of all schools among the target population.

Respondents, 27 of whom were full-time or part-time administrators (principals, vice-principals, head teachers) and 34 of whom were members of the English department (including 5 kokusai koryu tanto [students] who were officially in charge of their international exchange programs), returned the questionnaires by facsimile. In a few instances, follow-up contact was made to clarify ambiguous responses and to elicit more complete information.

\section{Validity}

Nearly all of the respondents (93\%) had participated in SA trips on at least one occasion and a large majority (74\%) on more than one occasion. They were therefore likely to be well acquainted with the planning and the outcomes of the programs. The existence of well-informed respondents in positions to provide expert opinions and observations about their OSPs supports an assumption of internal validity for this questionnaire. In other words, the data are meaningful and truly representative of the programs sampled, or to paraphrase Nunan, we are observing precisely what we think we are observing (1992, p. 81). As far as external validity is concerned, as mentioned above, no claim is made that the observations or conclusions of this survey research can be generalized beyond the defined population (namely, private junior high schools in Tokyo). Nevertheless, in the absence of significant differences between 
private junior high schools in Tokyo and in other metropolitan centers in Japan, it seems not unreasonable to assume that similar results might be obtained from other private junior high schools in Japan. Content validity is supported in that most of the questions are directly related to OSP features that have been frequently mentioned in the literature. Further reference to those sources is made in the discussion section below.

\section{Summary of Results}

\section{Respondents and Schools}

The first group of four questions examined respondents' experiences regarding OSPs, as well as some general characteristics of the schools, such as the number of pupils and the existence of special curricula (e.g., "English," "international communication") and whether there was any relationship between the existence of a special curriculum and an OSP. As mentioned above, results showed that respondents had participated in the OSPs on at least one occasion in 93\% of the cases, and on several occasions in $74 \%$ of the cases. There was an average of 378 pupils (from a range of 26 to 964) in the schools with OSPs and 482 in schools without programs. Moreover, a frequency comparison between larger and smaller schools (more or fewer than 426 pupils respectively) yielded a 5.71 Chisquare (significant at $p<.05$ ) indicating that smaller schools were more likely to have an OSP. A similar examination of schools by gender (boys, girls, co-ed) showed no significant difference in likelihood of having an OSP (Chi-square $=3.81$ ). Most $(95 \%)$ of the private junior high schools with OSPs implemented only a standard curriculum; however, one of the three schools with special curricula (international/English) was the school with the longest study abroad program (60 days).

\section{Time, Duration, and Destination of the OSP}

The second group of four items examined the broader "time and place" parameters of the program such as the number of years a program had been in existence, the destination countries, length of sojourns, and the times of year in which they took place.

Program histories averaged 12.4 years in length and ranged from 1 to 31 years $(\mathrm{SD}=8.4$ years). Of the 71 programs (nine schools had more than one program) only 15 had been in existence for more than 20 years, while 25 programs (35\%) had been created within the preceding 5 years. The most popular destinations were the U.S., New Zealand, and the U.K., 
with 21, 16, and 15 programs, respectively, followed by Australia with 9 and Canada with 7. There was also one OSP to each of Thailand, Ireland, and the U.S. territory of Guam, respectively. Sojourns lasted an average of 16.5 days ( $\mathrm{SD}=5.4$ days) and ranged in length from 5 to 29 days, with the exception of one program that lasted 60 days. The majority (70\%) of excursions took place in the summer (50 trips), while 13 trips occurred in the spring (18\%). The remaining 8 trips were in May, June, September, October, and November.

\section{Participating Pupils}

The five questions in this group of items addressed the age of the participants (school year), previous exposure to English (hours of instruction), whether English as a foreign language (EFL) conversation classes were part of the regular school curriculum, the number of pupils participating in the OSP, and the existence of a special selection process for participation.

In 47 out of 71 cases (66\%), participation was limited to third-year students (aged 14 and 15 years). Sixteen OSPs (22\%) combined 2nd- and 3rd-year pupils, and in one exceptional case with a high percentage of "returnees," a school implemented the OSP exclusively for first-year pupils. The numbers of participating pupils varied from as few as 5 to as many as $164(\mathrm{AVG}=38, \mathrm{SD}=39)$. In only five schools was there a selection process to screen students for participation on the basis of English proficiency.

Every school offered "conversation classes" but, depending upon the school year of the participants, time of departure, and school curriculum, there was a lot of variability in estimated hours of total EFL instruction (grammar, reading, and conversation) before departure, ranging from 234 to 800 hours (with an average of 462).

\section{Objectives, Activities, and Preparations for the OSP}

This section comprised eight questions concerning classification and objectives of the OSPs, predeparture orientation, integration between the OSP and the EFL program (in Japan), school visits, homestay arrangements, ESL lessons (in the host country), and support for pupils while they were in a homestay situation.

According to the Obunsha Guide to Junior High Schools, OSPs are classified as "international exchange" (kokusai koryu), "study abroad" 
(ryugaku koryu), "language study" (gogaku kenshu), "overseas study" (kaigai kenshu), and "graduation trips" (shugaku ryoko). While the first two are fairly general terms as far as short-term junior high school study abroad is concerned, language or overseas (culture) study imply more specific objectives, and graduation trips are intended primarily to cap off and commemorate the junior high school experience. The results for classification showed that "language study" was the official classification for 37 (52\%) of the OSPs surveyed (20 programs were classified as "language study" only, while 17 programs combined this with another classification). Eight schools classified their OSPs as "graduation trips," which is, at least ostensibly, related to a specific objective such as the learning of culture or language. However, when queried about specific objectives, respondents considered "language ability" the number one priority in only $29 \%$ of the cases, "cultural understanding" most often (58\% of the cases), and "school experience" hardly at all (1.2\%).

Most OSPs included visits to schools in the host country ( 48 out of 71 cases), and among these, $38 \%$ offered participation in Japanese as a foreign language (JFL) classes, 40\% arranged special ESL classes, and 33\% assigned "buddies" (multiple responses were possible, therefore the total does not add up to 100\%). Forty-three percent of schools claimed to integrate their EFL and OSP programs, employing host country-related materials, both authentic and specifically classroom-designed, such as photos taken by pupils on previous trips and audio materials, as well as planning lesson content relevant to the OSP.

With regard to predeparture orientation, 46 out of 61 schools (75\%) indicated that they provided some form of orientation to OSP participants, although five schools restricted this support to extra conversation practice, leaving only 41 out of 61 schools (67\%) providing extralinguistic predeparture information. Specifically, orientation to life in home-stay families (in applicable cases), explanation of local customs, or familiarization with local dialects and pronunciation were omitted in approximately $30 \%$ of the cases.

Homestay was a feature in 59 of 71 OSPs (83\%), with $86 \%$ of respondents citing cultural, and $51 \%$ linguistic benefits as the main reasons for including homestay (multiple response). Ease of supervision or cost savings were reasons in only $4 \%$ and $6 \%$ of the cases, respectively. Pupils were billeted or housed singly in $73 \%$ of homestays, reflecting the preference of the home institution in most cases. Reasons for preferring to billet their students singly rather than in pairs were fairly evenly distributed among "personal growth," "culture learning," and "language learning." 
Only about half (52\%) of the homestay OSPs reported efforts to provide special guidance to host families, although 14\% "didn't know" (suggesting that this might have been organized by the hosting side without the knowledge of the Japanese schools).

Special ESL lessons were provided in the host country in $58 \%$ of all OSPs, but in $75 \%$ of those OSPs officially classified as "language study" trips. These classes were an average of 75 minutes a day (including weekends; weekday averages would have been proportionately higher) with considerable variation; one OSP arranged more than three-and-ahalf hours per day, while some others only scheduled two hours (possibly only one or two sessions) during a 20-day sojourn. Moreover, in most cases (68\%), ESL lessons were "not at all" integrated with the EFL program in Japan.

\section{Follow-up and Evaluation of the OSP}

The final section of the survey asked about what happened after the pupils returned home to Japan. These questions considered pupils' follow-up activities as well as the organizers' own program evaluations. The last three questions invited comments regarding recent changes to the OSPs, special characteristics or achievements of the OSPs, or any notable problems or difficulties.

Upon their return to Japan, pupils completed "follow-up" assignments or activities in 66 of the 71 OSPs surveyed. Communicating with their homestay families (via the post or e-mail) and writing reports (in English or in Japanese) about their experiences were the most commonly cited ( $80 \%$ and $79 \%$, respectively). In $48 \%$ of the cases, the trip was featured in the school's annual culture festival, although it is not clear to what extent that was a teacher- or pupil-centered activity. In a further $29 \%$ of cases, teachers reported using the OSP experience either as the basis for a lesson plan or for reviewing the OSP in class.

"Evaluation" is less a feature of the OSP itself than of its administration. This item was included on the questionnaire because evaluations can provide schools with valuable data about how successful the programs are in meeting stated objectives and therefore better enable administrators to make informed decisions about improving their programs. Furthermore, the very existence of evaluations themselves might reflect a sincere desire on the part of administrators to derive the greatest benefit for the participating pupils and possibly for other stakeholders (e.g., schools, chaperoning teachers, host families) as well. As reported above, 66\% of 
the OSPs conducted some type of program evaluation, most commonly student and parent feedback, both of which could be said to belong to the "consumer satisfaction" variety of evaluation. These were reported in $79 \%$ and $55 \%$ of the cases, respectively (multiple responses) in which an evaluation took place. Such feedback is important because the survival of the program ultimately depends on whether it satisfies the participants and other stakeholders. Feedback from host families was obtained in only $19 \%$ of the OSPs with homestays. It may be the case, however, that the Japanese schools entrust the gathering of feedback from host families to affiliated schools or organizations in the host country.

Apart from participant feedback evaluations, two types of analytic evaluations were reported: pupil pre- and post-linguistic proficiency tests and attitude surveys. Of these, attitude surveys were reported in $50 \%$ of the cases that implemented evaluations. Linguistic proficiency tests were only reported by 4 out of 49 schools (8\%) that conducted evaluations and for only $6 \%$ of the 71 programs overall, certainly not in keeping with the $59 \%$ of OSPs that claimed to put a high priority on linguistic objectives.

\section{Discussion of Major Results}

The following discussion will focus on the "primary features" of OSPs, which are directly related to the amount and variety of linguistic or cultural exposure that the pupils receive, and which are therefore liable to have a direct effect upon the achievement of linguistic or cultural objectives. These four features are addressed in Question 8 (duration of the sojourn), Question 16 (visits to a local school), Question 19 (homestay), and Question 20 (ESL classes and their content integration).

\section{Duration of sojourn}

Duration of the sojourn, in particular, is an issue that strikes at the very heart of summer study exchange programs. Indeed, some scholars may question whether programs of short duration have any educational (linguistic or cultural) merit in the first place. Grove (1983), in reference to exchange programs that last shorter than one month, asserts, "Such exchanges ... hold little promise of accomplishing those high goals that most of us in the business of intercultural exchange hold dear" (p. 1). These concerns are echoed by Milleret (1990), who explains, "shortness of the summer study experience can limit student contact with the host 
culture [and]...the opportunity for language practice" (p. 483). Milleret, it should be noted, seems to be referring to programs lasting 5 to 6 weeks. Elsewhere, as cited above, Day (1987) also observes that one of the drawbacks of short programs is insufficient language practice or contact with the host culture.

However, for pupils in junior high schools surveyed for this study, the duration of summer OSPs is seldom a matter of 6 weeks, nor even an entire month; with one notable exception, every one of the OSPs examined lasted less than four weeks, and the average length was only 16.5 days. There was also much variability, with 12 programs lasting 10 days or less, and 25 programs lasting 3 weeks or longer. This raises several interesting questions: What accounts for the variability? Is there a relationship between participant satisfaction and duration? What sort of objectives can be achieved with shorter programs and is there a relationship between changes in attitude, for example, and length of sojourn even within the context of these very short OSPs? What are the costs and benefits of increasing program duration? While various constraints will inevitably continue to restrict the duration of summer study abroad programs for junior high school students, it is important to examine these programs more closely in order to discover what objectives can be reached, and how better to achieve these objectives within the time frames available.

\section{School visits}

Attending school in the host country, either on the basis of broader sister-school relationships or other arrangements with a host institute, is a common feature. While observing regular classes at a school can be very challenging for limited English proficient pupils, there is clearly potential for various types of linguistic exposure. In their study of Australian long-term (one year) high school exchange students in Japan, Marriott and Enomoto (1995) observed that "the school domain also provides...various opportunities for daily...communication and interaction" (p. 69). Elsewhere, Marriott has commented on the effects upon language learning that accrue to students who "participate in focused instruction in class as well as being immersed in the natural environment" (1995, p. 197). It is not clear that identical opportunities will exist for pupils on short-term visits, but certainly increasing the variety and amount of exposure to the language can only contribute to a richer, and therefore more beneficial, experience. 
It is not simply a question of whether or not to visit schools and observe classes, but of which classes and what sort of interaction occurs there. Marriott and Enomoto (1995) explain that while pupils had great difficulty coping with the content of most subjects, there were fewer difficulties in subjects such as English, physical education, or mathematics. For Japanese pupils overseas, classes in JFL, if they exist, might offer opportunities for active participation. The present survey revealed one interesting approach in which the visiting (Japanese) pupils acted as teaching assistants in JFL lessons for the pupils of the hosting school. It also revealed another innovative feature; some pupils visited an elementary school because it was believed that the linguistic challenge would be more suitable for their level of proficiency. Such program innovations should be explored in greater detail. Comparative program evaluations could be undertaken for the benefit of all those concerned with improving existing OSPs or planning new ones. Case studies utilizing qualitative research methods, including participant observation or interviews with teachers and program designers, could shed light upon activities that might be arranged to supplement or support classroom observation and what their potential benefits might be.

The survey also revealed a relationship between visits to southern hemisphere countries and the existence of school visits as OSP features. Currently, many of the excursions to the U.S., Canada, and the U.K. (according to this survey, 33 out of 42 , or $79 \%$ ) take place in the summer when schools in the host country are generally not in session. This suggests that scheduling excursions to northern hemisphere countries for the late winter or early spring would afford additional opportunities to coordinate OSPs with school visits and thus help achieve program objectives. By that time, pupils would also have had more hours of English instruction and there would be fewer conflicts with club activities, particularly sports clubs, many of which have important tournaments in the summer, as one of the respondents noted. While this may be of less interest to researchers, program administrators might wish to consider such alternative schedules.

\section{Homestays}

In an evaluation and review of summer study programs in 1990, Milleret reports that homestays are among "the major features of a summer language study abroad program that have been standardized through wide acceptance and implementation at both the high school and col- 
lege levels." (1990, p. 484). While there is, in fact, research that questions the value of a "homestay effect" (Freed, 1990; Rivers, 1998), learners themselves often feel there is benefit from the homestay context. Referring to Australian high school exchange pupils in Japan, Marriott and Enomoto (1995) noted that "exchange pupils themselves commonly claim that it is in the home context where their opportunity to acquire Japanese is maximized" (p. 68). In yet another survey of Australian learners of Japanese, Hashimoto (1994) reports that "eleven out of twenty pupils chose host families as the most helpful factor in their language acquisition, and seven pupils out of the remaining nine rated them second in importance. Consequently, most pupils considered the homestay to be very influential in relation to their language development" (p. 4).

Homestay is present in $83 \%$ of the programs examined in this survey. The extent to which this crowning feature is effective in promoting increased linguistic proficiency, improved attitudes to the target language or target language community, or greater crosscultural understanding, particularly with regard to very short-term programs for junior high school students, deserves further attention. The author is currently engaged in a study employing quantitative and qualitative methods to examine the effect of homestay upon listening comprehension and to describe the characteristics of that environment and the opportunities it provides for verbal interaction. That study will also address the potential for affecting interaction between homestay pupils and their host families through the appropriate use of communicative homework tasks. While it may turn out that a salient feature of this environment is its inherent variability, this may argue all the more for the development of homestay tasks or assignments designed to stimulate a certain basic level of verbal interaction. The development and analysis of such "homestay communicative tasks" itself is a potentially useful avenue for research.

\section{ESL lessons}

Just over half of all of the OSPs, but $75 \%$ of those that were officially classified as "language study," featured ESL classes. Milleret (1990) identifies language and culture classes taught at a local institute as one of the six standard features of summer language study abroad programs (p. 484). But the issue is not so much classroom learning itself as it is the role and function of these ESL classes within the specific context of study abroad, and particularly as a means of maximizing the opportunities that pupils may derive from naturalistic exposure to language resulting from home- 
stay. There should be a synergy between the more structured approach of classroom learning and the opportunities for genuine communication that arise out of homestay or other out-of-class environments in the host country. In other words, "a more porous classroom is required for foreign pupils studying in-country, one that guides more structured language learning and practice outside of the classroom...[and] the classroom should present opportunities to build upon the learning taking place outside" (Brecht \& Walton, 1994, p. 222).

Integration of the OSP, in general, and of ESL lessons (those provided in the host country) in particular, with the EFL program in Japan, are issues raised in Questions 17 and 20. This is not to suggest that these programs cannot be valuable and effective in their own right, rather, it is a question of missed opportunities. While the importance of adapting ESL lessons to the levels and needs of the pupils is beyond question, how much more effective might these lessons be if they maximized the opportunities for naturalistic exposure that the pupils encounter in their homestays? How much more practical, meaningful, and interesting would EFL lessons be if they integrated themes, needs, and situations arising out of OSPs that the pupils know their seniors have participated in and in which there is a distinct possibility that they, or their fellow pupils, might also join, in the future? Such improvements to EFL classes would benefit all the students, not only those who, for various reasons, were fortunate enough to participate. In this respect, it is disappointing to observe that the majority of schools (57\%) reported no integration at all between the OSPs and EFL programs and that with respect to integration of ESL lessons with EFL programs, 68\% of the OSPs showed no integration at all.

At the other extreme, ESL classes that merely repeat classroom experiences that pupils have already had in their home country, albeit with a different teacher and with a group of (hopefully) more highly motivated pupils, may serve relatively little purpose. If the lessons are tiresome, they may even be counterproductive. If they fail to provide unique learning opportunities, to stimulate verbal interaction within or reflection upon the homestay environment, and if their major value lies only in their face validity, then some important opportunities are being squandered. The evaluation of ESL classroom experiences that are offered as a part of OSPS also deserves study. How do these classes differ from the EFL classes that are offered in Japan? What can the teachers of those respective classes learn from each other? How can they reinforce each other's efforts? Is there a way to apply the experiences of the OSP to the EFL classroom so that all students can benefit from more interesting and meaningful classes? 


\section{Conclusion}

This comprehensive survey of junior high school SA programs in the Tokyo metropolitan area reveals a number of salient characteristics: Most of these programs are directed towards northern hemisphere countries, involve mainly 3rd-year pupils, take place during the summer months (July and August), and have an average duration of slightly more than two weeks. The stated objective for these programs is usually linguistic, although most informants feel that cultural objectives are at least, if not slightly more, important. Homestay, which is believed to support both linguistic and cultural objectives, figures prominently as the preferred style of accommodation. Program evaluations are largely limited to attitude questionnaires and pupil feedback and there is little effort to measure linguistic effect or cross-cultural awareness.

This paper has focused upon SA programs provided for junior high school pupils. As pointed out in the introduction, this age group has not been the subject of much research in the past. It is an important age group to study for at least three reasons. First, the relatively low level of English proficiency suggests that it may be easier to both achieve and measure changes in linguistic proficiency as a result of the SA experience than with older age groups. Providing evidence of a proficiency effect has been a difficult challenge for short-term study abroad, but there may be opportunities with junior high school OSPs, precisely because the participants are less proficient and thus are facing a steeper learning curve. Second, because these young pupils are at an impressionable age, there may be a greater potential to observe beneficial changes in attitudes towards the target language and culture, as well as increased integrative orientation. Whether these effects actually occur, and whether they are lasting effects, might also be fruitfully researched. Crosssectional attitude surveys comparing participants with non-participants over a 6-year period spanning junior and senior high school might reveal interesting results. Finally, this may be a particularly opportune time to bring about improved attitudes or integrative motivation since the pupils are at the threshold of their final three years of required English education. If the impact of this experiential education is such that the pupils approach those important remaining years with greater confidence, interest, and enthusiasm, then this result will go far towards justifying the continuation and improvement of these programs. 
Herbert Brauer has taught EFL in Japan for over 15 years and is a doctoral candidate in Applied Linguistics at the University of Birmingham.

\section{References}

Abrams, I., \& Hatch, W. R. (1960). Study abroad. New Dimensions in Higher Learning, 6. Washington, DC: U.S. Office of Education, Division of Higher Education.

Brecht, R.D., \& Walton, A.R. (1994). Policy issues in foreign language and study abroad. Annals of the American Academy of Political and Social Science, 532, 213-225.

Coleman, J A. (1997). Residence abroad within language study. Language Teaching, 30, 1-20.

Day, J.T. (1987). Student motivation, academic validity, and the summer language program abroad: An editorial. Modern Language Journal, 71, 261-266.

Drysdale, S., \& Killelea, F. (1982). Guide to conducting a language immersion / homestay program. New York: American Council on the Teaching of Foreign Languages.

Freed, B. F. (1990). Language learning in a study abroad context: The effects of interactive and non-interactive out-of-class contact on grammatical achievement and oral proficiency. In J. E. Alatis (Ed.), Georgetown University Roundtable on Language and Linguistics 1990 (pp. 459-477). Washington, DC: Georgetown University Press.

Geis, K. L., \& Fukushima, C. (1997). Overview of a study abroad course. The Language Teacher, 21 (11), 15-20.

Grove, C. (1982). Improving intercultural learning through the orientation of sojourners. AFS Occasional Papers in Intercultural Learning, No. 1. New York: AFS International / Intercultural Programs.

Grove, C. (1983). What research and informed opinion have to say about very short exchange programs (VSPS). New York: AFS International / Intercultural Programs.

Hashimoto, H. (1994). Language acquisition of an exchange student within the homestay environment. Journal of Asian Pacific Communication, 4(4), 128.

Higuchi, K., Saito, E., Lamarche, M., Shelangouski, R., \& Kikuchi, A. (1982). Crosscultural experiences of junior college students: Effects of homestay program. Sakura no Seibou Tankidaigaku Kiyo, 7, 147-156.

Kitao, S. K. (1993). Preparation for and results of a short-term overseas study program in the United States. Sogo Bunka Kenkyusho Kiyo, 10, 107-118.

Marriott, H. (1995). The acquisition of politeness patterns. In B. Freed (Ed.), Second language acquistion in a study abroad context (pp. 197-224). Amsterdam: John Benjamins. 
Marriott, H. \& Enomoto, S. (1995). Secondary exchanges with Japan: Exploring students' experiences and gains. Australian Review of Applied Linguistics Series, 12, 64-82.

Milleret, M. (1990). Evaluation and the summer language program abroad: A Review Essay. Modern Language Journal 74, 483-488.

Mombukagakusho (1998). Heisei 8 nendo kotogakko ni okeru kokusaikoryu nado no jokyo [International exchange among high schools in 1996]. Kyoiku Iinkai Geppo, 10 (9), 35-39.

Mombukagakusho (2001). On-line resource, Mobu tokei yoran [Ministry of Education Statistics Survey]. Retrieved May 11, 2002 from http://www.mext. go.jp/b_menu/toukei/002/002b/mokuji13.html

Nozaki, Y. (1987). Beikoku tanki ryugaku keiken ga oyobosu beikokujin, nihonjin imeji no henka [Changes in images of Americans and Japanese following a short-term study abroad experience in the US]. Sogo Bunka Kenkyusho Kiyo, 4, 46-66.

Nunan, D. (1992). Research methods in language learning. Cambridge: Cambridge University Press.

Obunsha (2001). Chugakko juken annai 2002 nyushyo [2002 guide to entrance examinations for junior high schools]. Tokyo: Obunsha.

Rivers, W. P. (1998). Is being there enough? The effects of homestay placements on language gain during study abroad. Foreign Language Annals, 31, 492500 .

Shiozawa, T. (2001). Ryugaku homusutei ni okeru kokusai koryu [International exchange with study abroad and homestay]. The English Teachers' Magazine (9), 16-18.

Stitsworth, M., \& Sugiyama, Y. (1990). International youth exchanges: Measuring their impact on attitudes. Paper presented at the Congress of the International Society for Intercultural Education, Training, and Research, Kilkenny, Republic of Ireland. (ERIC Document Reproduction Service No. ED331775)

Yashima, T., \& Viswat, L. (1991). A study of Japanese high-school students' intercultural experience: "It's not a dream country, but I love America." Change of image of Americans. Human Communication Studies, 19, 181194.

(Received August 30, 2003; accepted September 1, 2004) 


\section{Appendix I}

Questionnaire to private junior high schools with OSPs

\section{PART I: ABOUT THE RESPONDENT AND THE SCHOOL}

(1) How often have you accompanied the pupils on a study abroad trip to an English speaking country?
(a) once
(b) more than once
(c) never

(2) How many pupils are there in your school? boys girls

(3) What type of course or curriculum do you offer pupils at your school? (multiple response)
(a) standard
(b) international / English
(c) other

(4) In what course or curriculum are pupils who participate in overseas study programs enrolled?
(a) standard
(b) international / English
(c) other

\section{PART II: TIME, DURATION, AND DESTINATION OF THE OSP}

(5) When did your school first implement this study abroad program? Year

(6) What was the destination country of your most recent trip?

(7) In which month does the overseas program take place?

(8) What is the duration of the trip? days

\section{PART III: PARTICIPATING PUPILS}

(9) What school year are these participating pupils? (choose all that apply)
(a) first year
(b) second year
(c) third year

(10) How many hours of English instruction do your pupils receive per week (grammar, reading, conversation). 
(a) in first year third year hours (b) in second year hours (c) in hours

(11) Does your regular school program offer conversation classes? YES NO

(12) How many pupils participated in this program last year?

(13) Is there a special process for selecting the pupils?

(a) No. All pupils are accepted.

(b) Only if number of applicants exceeds spaces.

(c) Yes, to ensure a minimum level of language skills.

\section{PART IV: OBJECTIVES, ACTIVITIES, AND PREPARATION FOR THE OSP}

(14) Which classification best describes your overseas program?

(a) overseas study (b) linguistic study (c) graduation trip

(d) international exchange (e) sojourn exchange

(15) What are the program objectives? (rank as: 1 for most important, 2 for next most important, etc.)

_ (a) to provide a memorable school experience

_ (b) for better understanding of foreign culture

(c) to improve English ability

(d) for personal growth and development of the pupils

(16) Do your pupils visit a junior or senior high school at the destination? YES NO

(16a) IF YES, which of the following are true (check all that apply)

(a) your school has a formal "sister school" relationship with this school

(b) your pupils observe (audit) some regular classes at that school

_ (c) your pupils attend (participate) in some Japanese language classes 
(d) your pupils attend special ESL classes given at that school (e) your pupils are assigned a "buddy" from the host school (f) your school sponsors reciprocal visits to Japan for pupils from that school

(17) Is your regular English program integrated with the study abroad program? YES NO

(17a)IF YES, in which ways: (check all that apply)

_ (a) audio materials for listening practice related to the study abroad destination

_ (b) pictures / writings in classroom or halls from pupils who participated

_ (c) videos of school, lifestyles, culture etc. related to the study abroad destination

_ (d) lesson content is related to the host country or study abroad

_ (e) authentic materials (maps, menus, etc.) from host country used in lessons

(f) other

(18) Do you provide special orientation for pupils selected to participate in the visit? YES NO

(18a) IF YES, do you... (Check all that apply)

(a) explain family, social customs of the host country?

(b) familiarize pupils with features of typical English pronunciation or dialect at the destination

_ (c) prepare individual pupils about their particular host families (in case of homestay)?

_ (d) give extra conversation practice by reading dialogues (e) give extra conversation practice by memorizing words or phrases 
__ (f) give extra conversation practice by doing role play or simulations

(19) Does your program provide arrangements for homestay visits? YES NO

(19a)If yes, why do you provide such arrangements?

(main reason - choose one only)

_ (a) more economical

_ (b) difficult to arrange other types of accommodation

_ (c) better for learning English

_ (d) better for learning culture

_ (e) easier to supervise pupils

(f) other

(19b) If yes, how many pupils stay with a single family?

(a) one _- (b) two

__ (c) combination __ $\% 1$ pupil; __ $\% 2$ pupils

(19c) If yes, which type of accommodation arrangements do you think is best, and why?
(a) homestay (1 pupil) (b) homestay (2 pupils)
(d) other
(c) dormitory

Reason:

(19d) If yes, do host families receive guidance on communicating with low English proficiency guests?
(a) YES
(b) $\mathrm{NO}$
(c) DON'T KNOW

(20) Do the pupils receive special English lessons while they are abroad? YES NO

(20a) IF YES, how many hours instruction (total) hours

(20b) IF YES, how closely does lesson content integrate with your regular English program? 
(a) very closely - lesson review or build directly upon our own lessons

(b) somewhat - lesson materials are designed to match the level and content of our classes

_ (c) not at all - there is no particular consideration to our syllabus and lesson content

(21) Do you offer your pupils personal or linguistic support during their sojourn? YES NO

(21a) In what ways do you support them? (check all that apply)

_ (a) you contact the host families on a regular basis

_ (b) the pupils can contact you if they have difficulties

_ (c) the pupils meet their accompanying teachers on a regular basis

_ (d) pupils are given a telephone number to use in an emergency

_ (e) you have regular problem discussion / solving sessions with the pupils

_ (f) other

PART V: RESPONDENT'S OPINION ABOUT THE OSP AND PARTICIPATING PUPILS

(22) Our pupils are mature enough to benefit from the cultural experience

(a) agree strongly (b) agree somewhat (c) neutral

(d) disagree somewhat (e) disagree strongly

(23) Our pupils are mature enough to benefit from homestay (omit this if you don't use homestay)

(a) agree strongly (b) agree somewhat (c) neutral

(d) disagree somewhat (e) disagree strongly

(24) The sojourn is long enough to achieve a noticeable effect upon their ablity to speak and understand English. 
(a) agree strongly (b) agree somewhat (c) neutral

(d) disagree somewhat (e) disagree strongly

(25) The sojourn is long enough to achieve a significant effect upon their attitudes toward host country / culture.

(a) agree strongly (b) agree somewhat (c) neutral

(d) disagree somewhat (e) disagree strongly

(26) These study trips are an effective way of improving pupils' attitudes towards the target culture / language.

(a) agree strongly (b) agree somewhat (c) neutral

(d) disagree somewhat (e) disagree strongly

(27) Homestay is an effective way of improving pupils' listening and speaking skills.

(a) agree strongly (b) agree somewhat (c) neutral

(d) disagree somewhat (e) disagree strongly

(28) ESL lessons in the host country (as part of our program) are effective in improving listening and speaking skills.

(a) agree strongly (b) agree somewhat (c) neutral

(d) disagree somewhat (e) disagree strongly

(29) Attending regular school classes in host country as observers effectively improves listening and speaking skills.

(a) agree strongly (b) agree somewhat (c) neutral

(d) disagree somewhat (e) disagree strongly

\section{PART VI: FOLLOW-UP AND EVALUATION OF THE OSP}

(30) Do the pupils follow up their study abroad experience? YES $\mathrm{NO}$

(30a) IF YES, how do they follow it up? (check all that apply)

(a) pupils write reports about their experiences

(b) pupils correspond (email or post) with friends in the host country

_ (c) trip is reviewed in English classes

(d) trip is a highlight of the annual Culture Festival 
(e) experiences from the trip help create ideas for lesson plans or teaching points

(31) Have you attempted to evaluate your program? YES NO

(31a) IF YES, which instruments have you used to perform the evaluation? (check all that apply)

__ (a) student feedback or evaluations

_ (b) parent feedback or evaluations

_ (c) host family feedback or evaluations

_ (d) host institution feedback or evaluations

_ (e) student before and after proficiency tests

_ (f) student before and after attitude surveys

(32) Have there been any major changes in your program recently? (e.g. number of students, period of sojourn, number of students electing solo homestay) Please explain.

(33) Are there any particularly successful features or special characteristics of your program? Please explain.

(34) Are there any particular problems you have encountered? Please explain.

Thank you very much for your time and effort.

The original Japanese-language version of this questionnaire is available from the author at heb2278@yahoo.com 
